\title{
Photic Regulation of Peptides Located in the Ventrolateral Subdivision of the Suprachiasmatic Nucleus of the Rat: Daily Variations of Vasoactive Intestinal Polypeptide, Gastrin-releasing Peptide, and Neuropeptide $Y$
}

\author{
Kazuyuki Shinohara, ${ }^{a}$ Keiko Tominaga, ${ }^{b}$ Yoshiaki Isobe, ${ }^{c}$ and Shin-Ichi T. Inouye \\ Laboratory of Integrative Brain Function, Mitsubishi Kasei Institute of Life Sciences, Machida, Tokyo 194, Japan
}

We have determined, by enzyme immunoassay, daily and circadian patterns of the concentrations of three peptides, which are located in the ventrolateral subdivision of the suprachiasmatic nucleus (SCN): vasoactive intestinal polypeptide (VIP), gastrin-releasing peptide (GRP), and neuropeptide $Y$ (NPY). The contents of VIP and GRP, which are synthesized in the SCN, did not show circadian rhythms in constant darkness (DD). Under light-dark (LD) conditions, GRP content increased and VIP content decreased over the course of the light period and then gradually recovered during the dark period. Responsiveness of these peptides to light suggests that VIP and GRP may transmit visual information on duration of illumination. NPY, which is transported from the intergeniculate leaflet cf the lateral geniculate body, showed a circadian rhythm with a peak at circadian time 12 hr in DD. This endogenous rhythm was remarkably modulated by photic stimulation. Under LD conditions, the NPY content in the SCN exhibited a bimodal rhythm with peaks at both the light-dark and dark-light transition points. Thus, NPY may convey visual information on the transitions. All these results indicate that the levels of VIP, GRP, and NPY are mainly regulated by light stimulation and suggest that peptides in the ventrolateral $\mathrm{SCN}$ are involved in the mediation of photic information to the pacemaker.

IKey words: circadian rhythm, entrainment, suprachiasmatic nucleus, vasoactive intestinal polypeptide, gastrinreleasing peptide, neuropeptide $Y$, enzyme immunoassay]

In mammals, the suprachiasmatic nucleus of the hypothalamus (SCN) has been identified as a circadian clock system. The system consists of a central pacemaker and an entraining machin-

Received Jan. 31, 1992; revised Aug. 10, 1992; accepted Aug. 14, 1992.

We thank Drs. W. J. Schwartz and F. W. Turek for their helpful discussions, Dr. H. Mitsushio for his donating VIP antiserum, and Miss A. Tokumasu for her technical assistance. This work was supported by Mitsubishi Kasei Institute of Life Sciences Grant Project No. 10.

Correspondence should be addressed to Kazuyuki Shinohara, Laboratory of Integrative Brain Function, Mitsubishi Kasei Institute of Life Sciences, Minamiooya 11, Machida, Tokyo 194, Japan.

aPresent address: Department of Pharmacology, Tokai University Medical School, Iseliara, Kanagawa 259-11, Japan.

'Permanent address: Department of Pharmacology, Faculty of Pharmaceutical Sciences, Kyushu University, Maidashi, Fukuoka 812, Japan.

cPermanent address: Department of Physiology, Nagoya-city University Medical School, Mizuho, Nagoya 467, Japan.

Copyright $@ 1993$ Society for Neuroscience $0270-6474 / 93 / 130793-08 \$ 05.00 / 0$ ery. The pacemaker endogenously generates approximate $24 \mathrm{hr}$ rhythms, and the entraining machinery adjusts the phases of the rhythms to local environmental time. One might imagine that these distinct functions, rhythm generation and entrainment, are carried out in separate subfields of the SCN. We address this possibility in the present article.

Anatomically, the SCN is composed of two subdivisions, which are distinguished by the differential concentrations of chemically distinct ncurons as well as the terminal arborization of visual afferents (Van den Pol, 1980; Moore and Card, 1985). The dorsomedial aspect of the SCN contains arginine-vasopressin (AVP)and somatostatin (SS)-immunoreactive neurons and lacks visual inputs. Previous studies have revealed a clear circadian rhythm of AVP-like immunoreactivity (LI) in the SCN (Sodersten et al., 1985; Tominaga et al., 1992). We have also recently demonstrated a circadian rhythm of SS-LI in the SCN (Shinohara et al., 1991a). In addition to these pieces of evidence, a lesion study (Van den Pol and Powley, 1979) and an electrophysiological study (Shibata et al., 1984) critically discussed how the dorsomedial SCN might play a role in internal generation of circadian rhythms or in outward mediation of the generated rhythms.

The ventrolateral aspect of the SCN contains neurons immunoreactive for vasoactive intestinal polypeptide (VIP), gastrin-relcasing pcptide (GRP), and ncuropcptide Y (NPY) (Van den Pol and Tsujimoto, 1985). NPY is synthesized in the intergeniculate leaflet of the lateral geniculate body and transported to the SCN (Moore and Card, 1985). As for VIP and GRP, their cell bodies are found in the SCN and some of their axons are involved in local circuit interactions between neurons within the nucleus (Van den Pol and Gorcs, 1986; Okamura et al., 1987). Furthermore, VIP and GRP were shown to be colocalized in some SCN neurons (Okamura et al., 1986).

The ventrolateral subdivision of the SCN is also characterized by the termination of visual afferents directly from the retina via the retinohypothalamic tract or indirectly via the geniculohypothalamic tract (Moore and Card, 1985). The selective distribution of visual projections within a subdivision of the nucleus makes it tempting to hypothesize that the ventrolateral SCN may be involved in the process of photic entrainment. Albers and Ferris (1984) showed that NPY injections induced phase shifts in subsequent locomotor activity rhythm in hamsters. Albers et al. (199lb) recently reported that coadministration of VIP, peptide histidine isoleucine amide (PHI), and GRP caused phase shifts in hamster locomotor activity rhythms. These 
a) $\mathrm{DD}$

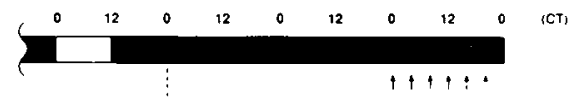

b) LD

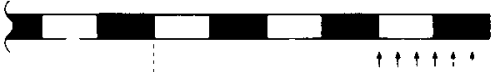

c) Continuous light exposure

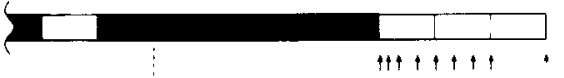

d) Continuous dark exposure

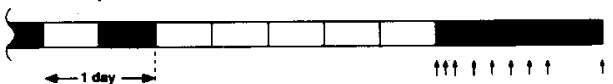

Figure 1. Time schedule of lightings and samplings in the present study. All rats were entrained to $12 \mathrm{hr} / 12 \mathrm{hr} \mathrm{LD}$ cycles for 2 weeks. In the DD experiments $(a)$, they were transferred to total darkness. On the third day of free running, the animals were killed at $4 \mathrm{hr}$ intervals for determination of peptide contents in the SCN. In the LD experiment (b), they were kept in the LD cycle and killed during the day. In the continuous light exposure experiments $(c)$, the animals were first transferred to constant darkness for $2 \mathrm{~d}$ and then exposed to light at CTO. They were killed at $0,1,2,4,8,12,16,20,24$, and $36 \mathrm{hr}$ after light onset. Samplings in this experiment of NPY were not done at $36 \mathrm{hr}$ after light on. In the continuous dark exposure experiments $(d)$, they were exposed to illumination for $2.5 \mathrm{~d}$ before transferred to the total darkness at CT 12. Sampling was done at 0, 2, 4, 8, 12, 16, 20, and 24 $\mathrm{hr}$ after dark onset. Arrows indicate time of sampling. Open bars represent the light period; solid bars, the dark period.

studies assessed effects of peptides on the rhythm, which are postsynaptic events. In the present study, we determined changes in peptide contents in the ventrolateral SCN under different lighting conditions, in order to evaluate the effect of lighting conditions on the peptide levels in the SCN, which are presynaptic crents.

Although several groups have independently performed experiments on the effect of light exposure on VIP-LI (Albers et al., 1987) in the SCN and the daily variation of VIP-LI (Morin et al., 1991) and NPY-LI (Jhanwar-Uniyal et al., 1991) in the rat SCN during the light-dark (LD) cycle, temporal profiles of VIP-LI and NPY-LI have not been determined under other conditions. To our knowledge, no information about the daily pattern of GRP-LI in the SCN is available. Therefore, to determine whether peptides in the ventrolateral $\mathrm{SCN}$ are regulated by the LD cycle or by the circadian pacemaker, we measured daily variations of VIP-, GRP-, and NPY-LI in the rat SCN under LD or constant dark (DD) conditions by enzyme immunoassay (EIA). Furthermore, to elucidate photic effects on the levels of the peptides in detail, we also studied the time course of changes in peptide levels in the SCN of rats continuously exposed to light or darkness for 1-36 hr.

\section{Materials and Methods}

Animals. Male Wistar rats (SLC Co., Shizuoka, Japan), 5 weeks postpartum at purchase, were housed three to a cage with free access to food and water and maintained under $12 \mathrm{hr}$ light/12 hr dark cycle (light on at 09:00, off at 21:00) for 2 weeks. Experimental protocols for light conditions are illustrated in Figure 1 . One group of rats (Fig. $1 b$ ) was killed under light-dark (LD) conditions at $4 \mathrm{hr}$ intervals. Another group of rats (Fig. 1a) was transferred from this LD regimen to constant darkness $48 \mathrm{hr}$ prior to the experiments. They were killed at $4 \mathrm{hr}$ intervals during the third day of free running under constant dark (DD) conditions. For the experiment on the time course of the light (Fig. 1c) or dark (Fig. 1d) cffect, we exposed the other group of rats to continuous light or darkness after they were transferred from the LD cycle to constant darkness or light $2 \mathrm{~d}$ prior to the experiment. Then the lights were turned on at circadian time 0 (CT0) for continuous light exposure or turned off at CT12 for continuous dark exposure in order to study continuous peptide expression after prolonged exposure to constant lighting conditions. Light was provided by fluorescent bulbs, and its intensity was approximately 400 lux at the center of the cage. In the animals used for DD, continuous light, and dark exposure experiments, we assigned CT0 and CT12 to 09:00 and 21:00, respectively, because locomotor activity measurements showed that the $2 \mathrm{~d}$ of free running did not shift the phase of the animal's rhythm longer than $0.5 \mathrm{hr}$.

Tissue preparation. Rats were killed by decapitation and their brains were rapidly removed. In those rats killed in darkness, decapitation was done in dim red light and the optic nerves were severed before the brain was removed under the light. One-millimeter-thick sections were obtained using razor blades and Rodent Brain Matrix (Activational Systems Inc., Michigan) and frozen on a silicon rubber plate cooled by dry ice. The pair of entire SCNs for one animal were bilaterally punched out from a frozen slice under a stereomicroscope with a microdissecting needle with an inside diameter of $400 \mu \mathrm{m}$. We placed the punching needle on the ventral edge of the slices in order to eliminate possible contamination from the periventricular or anterior hypothalamic nucleus, which contains a large amount of VIP, GRP, and NPY (Palkovits and Brownstein, 1985). Further, each slice was scrutinized and samples were eliminated if the punched hole on the slice invaded the periventricular or anterior hypothalamic nucleus. Tissues were stored at $-80^{\circ} \mathrm{C}$ until use.

Chemicals and other materials. The sources of the reagents are as follows: synthetic VIP, GRP, and NPY, the Peptide Institute, Inc., Japan; rabbit antiserum against GRP and NPY, the Peptide Research Foundation, Japan; goat antiserum against rabbit IgG, Shibayagi Co. Ltd., Japan; horseradish peroxidase (HRP), Toyobo Co. Ltd., Japan; $o$-phenylenediamine dihydrochloride (OPD) from Sigma Chemical Co. Rabbit antiserum against VIP was generously provided by Dr. H. Mitsushio, Institute of Neuroscience. The antiserum is specific for VIP in that it cross-reacts less than $0.05 \%$ with the related gut peptides secretin, glucose-dependent insulinotropic peptide, peptide histidine isoleucine, and glucagon. Other antisera are characterized by Peptide Institute, Inc. Cross-reaction of GRP antiserum against neuromedin $\mathrm{C}$ or bombesin is $10 \%$, and that of neuromedin $B$ or peptide $Y Y$ is less than $0.1 \%$. Cross-reaction of NPY antiserum against pancreatic polypeptide and peptide YY is less than $0.1 \%$. Other chemicals used were all of highest purity commercially available. Ninety-six F Multi Well Plates for ELISA (microplate) were purchased from Sumitomo Bakelite Co. Ltd., Japan.

Tissue extraction. The tissues were boiled in 1 м acelic acid containing $20 \mathrm{~mm} \mathrm{HCl}$ for $10 \mathrm{~min}$ to inactivate intrinsic proteinases. After cooling, they were homogenized for $30 \mathrm{sec}$ by sonication (Handy sonic; Tomy Ltd., Japan) and centrifuged at $10,000 \times g$ for $10 \mathrm{~min}$. An aliquot of the supernatant was lyophilized and stored at $-20^{\circ} \mathrm{C}$ until enzyme immunoassay (EIA).

EIA procedure. EIA of VIP, GRP, and NPY was performed in a manner similar to the method previously described (Shinohara et al., $1991 \mathrm{~b}$ ). In brief, the standard buffer for EIA was $0.14 \mathrm{M}$ phosphate buffer (pH 7.4) containing $25 \mathrm{~mm}$ EDTA, $0.5 \%$ bovine serum albumin, and $0.05 \%$ Tween 20 . Separation of the bound and free fraction was obtained by a double-antibody solid-phase method using a microplate coated with the goat antiserum against rabbit IgG. The EIA incubation mixture in each well of microplate consisted of $100 \mu$ l standard buffer, $50 \mu \mathrm{l}$ of either the standard or the sample solution, and $50 \mu \mathrm{l}$ of appropriately diluted antiserum (VIP, 1:100,000; GRP, 1:50,000; NPY, $1: 125,000)$. The mixture was incubated overnight at $4^{\circ} \mathrm{C}$ and then 50 $\mu 1$ of appropriately diluted HRP-peptide conjugate (VIP, 1:2000; GRP, 1:2000; NPY, 1:1000) was added and allowed to react at $4^{\circ} \mathrm{C}$ for $3 \mathrm{hr}$. Each well of microplate was then washed three times with washing buffer $(0.02 \mathrm{M}$ phosphate-buffered saline, $\mathrm{pH} 7.4)$ and incubated with $250 \mu \mathrm{l}$ of substrate $\left(73.6 \mathrm{mg}\right.$ of OPD and $100 \mu \mathrm{l}$ of $3 \% \mathrm{H}_{2} \mathrm{O}_{2}$ prepared in 100 $\mathrm{ml}$ of $0.2 \mathrm{M}$ citrate phosphate buffer, $\mathrm{pH} 5.2$ ) at room temperature for $50 \mathrm{~min}$. The reaction was terminated by adding $50 \mu 1$ of $5 \mathrm{~N} \mathrm{H}_{2} \mathrm{SO}_{4}$ to each well. The absorbance of the resulting reaction product was measured by an EIA reader (model 2550, Bio-Rad) at $492 \mathrm{~nm}$. The sensitivities of the assays at $90 \%$ relative binding rate of antigen $\left(B / B_{0}\right)$ levels were as follows: VIP, $1.0 \mathrm{fmol} /$ well; GRP, $1.4 \mathrm{fmol} /$ well; NPY, $3.0 \mathrm{fmol} /$ well. Williams-Wilcoxon test was used for statistical analysis.

\section{Results}

Vasoactive intestinal polypeptide. The circadian pattern of VIPLI within the SCN of rats housed under DD conditions is shown 
in Figure $2 a$. No significant change was seen in the SCN content of VIP-LI at different times during the day, with a value of 137 $\pm 7 \mathrm{fmol} / \mathrm{SCN}$. Under diurnal lighting conditions, VIP-LI in the SCN exhibited a conspicuous daily rhythm, as shown in Figure $2 b$. VIP-LI began to decrease from $120 \pm 8 \mathrm{fmol} / \mathrm{SCN}$ at lights on (CT0) to $77 \pm 7 \mathrm{fmol} / \mathrm{SCN}$ at lights off (CT12) and then gradually recovered throughout the night. The values at CT4, CT8, and CT12 were significantly different $(p<0.01)$ from that at CT0. To examine the time course of the VIP-LI level in response to light, we ncxt presented light stimuli for various durations from CTO to rats that had been kept under DD conditions for $48 \mathrm{hr}$. In Figure $2 c$, light stimuli were continuously delivered until the time of sampling. After lights on, VIP-LI content rapidly decreased in $4 \mathrm{hr}$ from $153 \pm 8$ to 113 $\pm 3 \mathrm{fmol} / \mathrm{SCN}(p<0.01)$ and then gradually decreased to a trough of $71 \pm 8 \mathrm{fmol} / \mathrm{SCN}$ at $16 \mathrm{hr}$ after light onset. Even though animals were continuously exposed to light stimuli for more than $16 \mathrm{hr}$, VIP-LI level in the SCN remained low for at least $36 \mathrm{hr}$. The suppressed level of VIP-LI in the SCN was $46 \%$ of the initial level. Thus, the time course of VIP-LI in response to light revealed that the daily pattern of VIP-LI in the SCN under LD conditions is actually caused by the environmental light-dark cycle.

Gastrin-releasing peptide. Under DD conditions, GRP-LI did not exhibit any significant variations in the rat $\mathrm{SCN}$ and stayed at constant values of $8.9 \pm 0.9 \mathrm{fmol} / \mathrm{SCN}$ (Fig. $3 a$ ). As shown in Figure $3 b$, GRP-LI increased progressively during the light period and decreased during the dark period with a range of variations from $9.5 \pm 0.8$ to $12.8 \pm 0.5 \mathrm{fmol} / \mathrm{SCN}$. The differences between CT0 and CT 8 or CT12 were statistically significant $(p<0.1)$. These changes in GRP-LI in the LD cycle were in a direction opposite to those of VIP-LI. To examine whether the GRP-LI rhythm under LD conditions was accounted for by light exposure lasting $12 \mathrm{hr}$, light stimuli were delivered continuously from CT0 as long as $36 \mathrm{hr}$ to rats that had been kept in darkness for $48 \mathrm{hr}$. As illustrated in Figure $3 c$, GRP-LI rapidly increased in response to light from $8.7 \pm 0.5 \mathrm{fmol} / \mathrm{SCN}$ to 13.3 $\pm 0.8 \mathrm{fmol} / \mathrm{SCN}$ and reached a plateau at CT12. Thus, there is a 1.5-fold difference between the initial and peak values of GRPLI in the SCN. GRP-LI levels significantly increased $(p<0.1)$ $4 \mathrm{hr}$ after initial light exposure and remained at significantly higher levels $(p<0.01)$ thereafter. A comparison of the three graphs in Figure 3 indicates that the daily variation of GRP levels in the SCN is a simple response to the ambient LD cycle.

Neuropeptide $Y$. NPY-LI showed a circadian rhythm in the SCN in DD with a peak of $77.1 \pm 4.7 \mathrm{fmol} / \mathrm{SCN}$ at CT12 and

Figure 2. $a$, Circadian profile of VIP-LI in the SCN under DD conditions. Points and bars represent the means $\pm S E$ of three independent measurements. The SCNs for a determination were pooled from three animals and assayed in triplicate by EIA. Values are expressed as femtomoles per bilateral SCNs of an animal. $b$, Daily pattern of VIP-LI in the SCN under LD conditions. Points and bars represent the means \pm SE of three independent measurements. The SCNs for a determination were pooled from three animals and assayed triplicate by EIA. Values are expressed as femtomoles per bilateral SCNs of an animal. $c$, Time course of the effect of continuous light exposure on VIP-LI in the SCN. Following various durations (1-36 hr) of light exposure starting at CT0, VIP-LI levels were measured in the SCN. Protocol of illumination is illustrated in Figure 1c. Points and bars represent the means $\pm \mathrm{SE}$ of three independent measurements. The SCNs for a determination were pooled from three animals and assayed in triplicate by EIA. Values are expressed as femtomoles per bilateral SCNs of an animal.
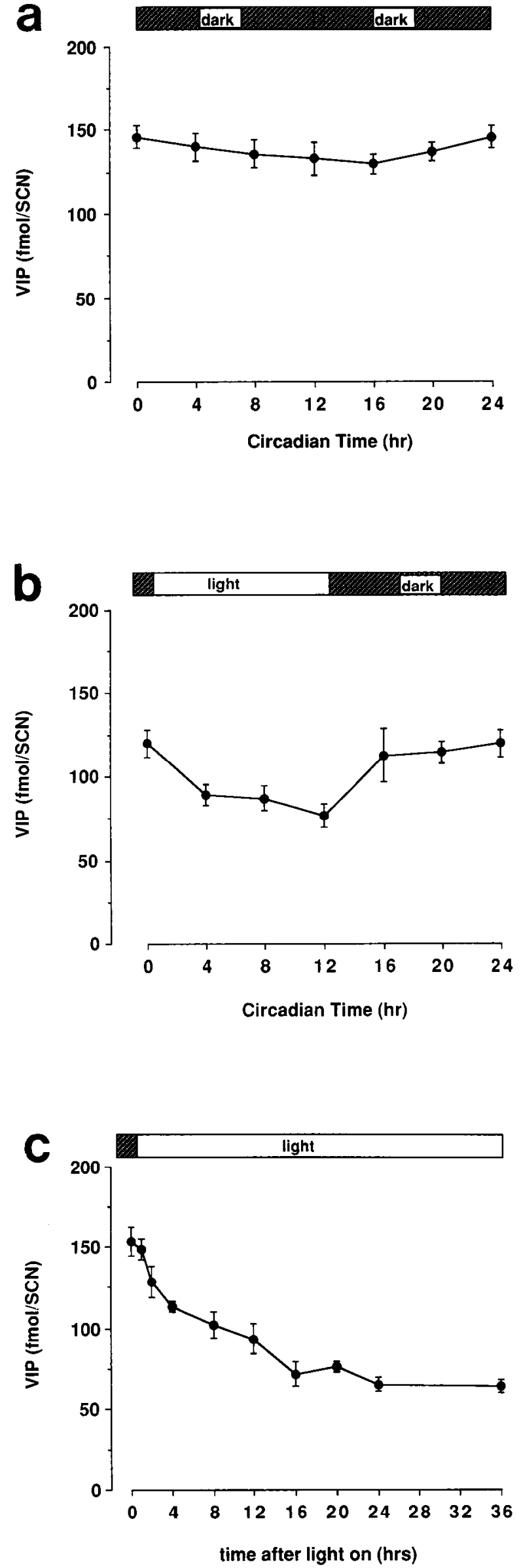

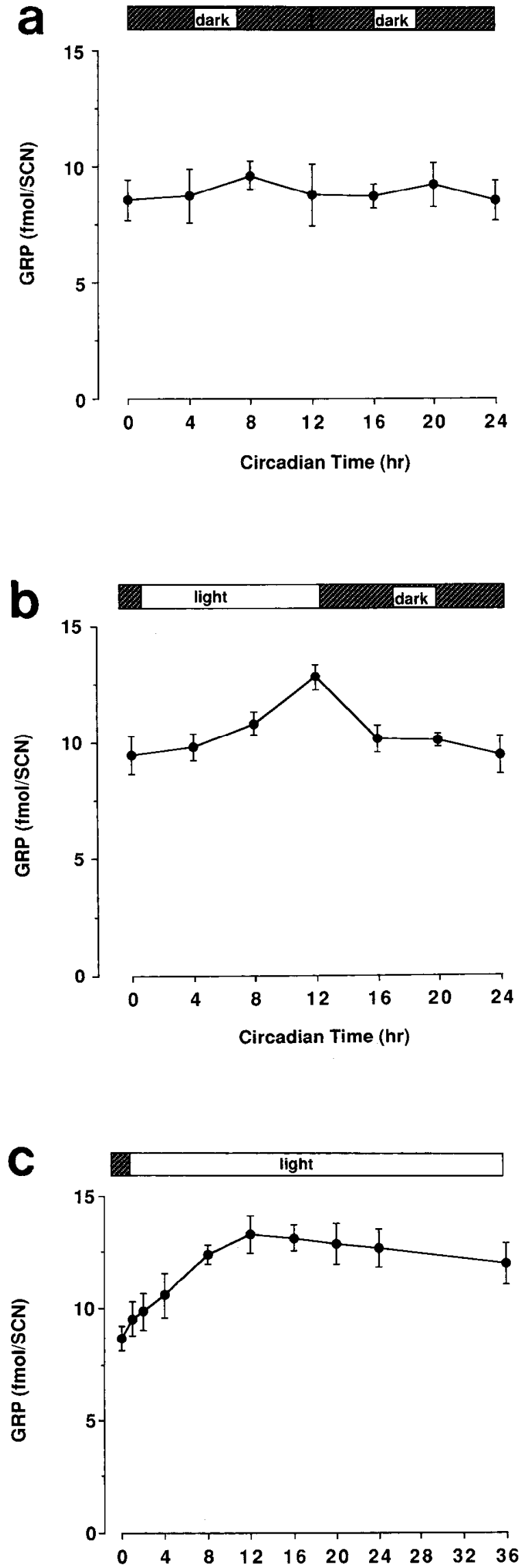

time after light on (hrs) a trough of $51.4 \pm 3.6 \mathrm{fmol} / \mathrm{SCN}$ at CT0 (Fig. $4 a$ ). The peak value at $\mathrm{CT} 12$ and trough value at $\mathrm{CT} 0$ were found to be significantly different $(p<0.01)$. Differences in NPY-LI between CT0 and CT8 $(p<0.05)$, CT16 $(p<0.1)$, and CT20 $(p<0.05)$ were also found statistically significant. Under LD conditions, we observed a daily bimodal profile in NPY-LI (Fig. 4b). In comparison with the value at CT0, NPY levels were significantly higher at CT2, CT4, and CT14 $(p<0.01)$. The peaks were found at CT2 (first peak) and CT14 (second peak), $2 \mathrm{hr}$ after light onset and $2 \mathrm{hr}$ after light offset, respectively. The first peak value was $94.8 \pm 5.2 \mathrm{fmol} / \mathrm{SCN}$, and the second peak value was $82.3 \pm 5.8 \mathrm{fmol} / \mathrm{SCN}$. To investigate further the properties of the individual peaks, we exposed rats to continuous light after $2 \mathrm{~d}$ of darkness or to continuous darkness after $2 \mathrm{~d}$ of light and assessed the time courses of NPY-LI levels in the SCN. When the rats were continuously exposed to light from CTO, NPY-LI significantly increased $(p<0.01)$ from an initial value of 61.4 $\pm 9.1 \mathrm{fmol} / \mathrm{SCN}$ to the maximal value of $104.3 \pm 4.4 \mathrm{fmol} /$ $\mathrm{SCN}$ in $2 \mathrm{hr}$ and then rapidly decreased to the initial level after $4 \mathrm{hr}(p<0.05)$ even though the light remained on (Fig. $4 c)$. The NPY level continued to decrease further until it reached a trough level of $46.0 \pm 3.2 \mathrm{fmol}$ after $12-16 \mathrm{hr}$ and was then gradually restored to the initial level by $24 \mathrm{hr}$, although these changes were not significant. When rats were continuously exposed to darkness from CT12, levels of NPY-LI again transiently increased after $2 \mathrm{hr}$ to the maximum of $95.1 \pm 6.5 \mathrm{fmol} /$ $\mathrm{SCN}$ and returned to the initial level after $4 \mathrm{hr}$ (Fig. $4 d$ ). When the rats were further kept in darkness, NPY-LI in the SCN remained at low levels for at least $24 \mathrm{hr}$.

\section{Discussion}

In the present study, we have demonstrated daily rhythm in VIP-LI and GRP-LI in the SCN under LD conditions and no rhythms in DD. NPY-LI in the SCN showed an endogenous rhythm in DD and a bimodal rhythm under LD conditions. These results suggest a common feature that all three peptides in the ventrolateral SCN share. Daily profiles of these peptides under DD conditions were remarkably different from those under LD conditions. Since changes in peptide contents could result from synthesis, degradation, and/or release, it is difficult to attribute the rhythms we found in the present study to one source. Howcver, recent studics have suggested that peptide contents in the SCN may follow the changes in its mRNA levels with several hours phase lag, as demonstrated with SS (Shinohara et al., 1991a; Takeuchi et al., 1992). On the other hand, corresponding changes in the release and content of peptides in the SCN were suggested by the reports showing that AVP con-

Figure 3. a, Circadian profile of GRP-LI in the SCN under DD conditions. Points and bars represent the means $\pm \mathrm{SE}$ of three independent measurements. The SCNs for a determination were pooled from three animals and assayed in triplicate by EIA. Values are expressed as femtomoles per bilateral SCNs of an animal. $b$, Daily pattern of GRP-LI in the SCN under LD conditions. Points and bars represent the means \pm SE of three independent measurements. The SCNs for a determination were pooled from three animals and assayed in triplicate by EIA. Values are expressed as femtomoles per bilateral SCNs of an animal. $c$, Time course of the effect of continuous light exposure on GRP-LI in the SCN. Following various durations $(1-36 \mathrm{hr})$ of light exposure at CT0, GRP-LI levels were measured. Protocol of illumination is illustrated in Figure 1c. Points and bars represent the means $\pm \mathrm{SE}$ of three independent measurements. The SCNs for a determination were pooled from three animals and assayed in triplicate by EIA. Values are expressed as femtomoles per bilateral SCNs of an animal. 

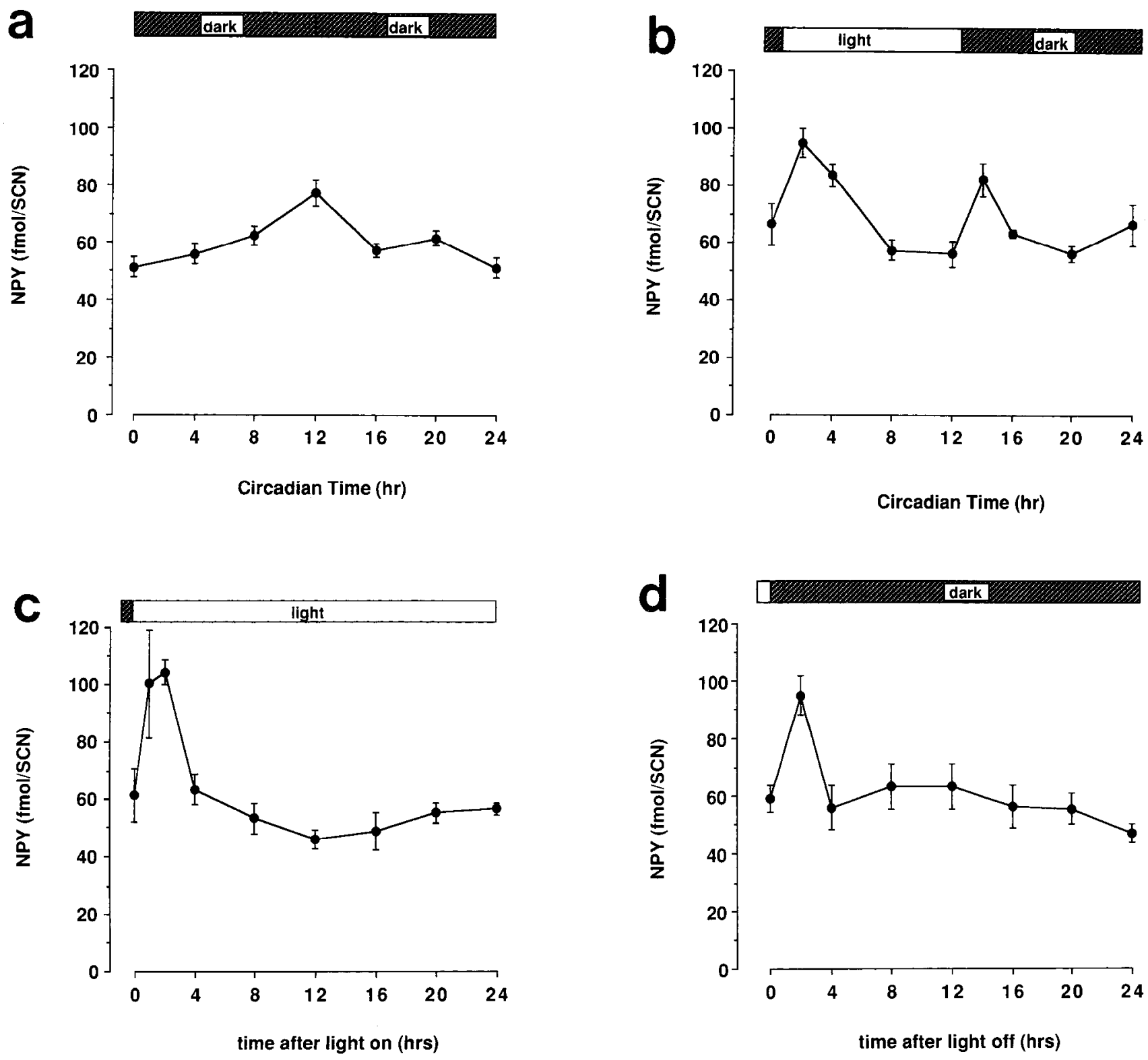

Figure 4. a, Circadian profile of NPY-LI in the SCN under DD conditions. Points and bars represent the means \pm SE of three independent measurements. The SCNs for a determination were pooled from three animals and assayed in triplicate by EIA. Values are expressed as femtomoles per bilateral SCNs of an animal. $b$, Daily patterns of NPY-LI in the SCN under LD conditions. Points and bars represent the means \pm SE of three independent measurements. The SCNs for a determination were pooled from three animals and assayed in triplicate by EIA. Values are expressed as femtomoles per bilateral SCNs of an animal. $c$, Time course of the effect of continuous light exposure on NPY-LI in the SCN. Following various durations (1-24 hr) of light exposure at CT0, NPY-LI levels were measured. Protocol of illumination is illustrated in Figure $1 c$. Points and bars represent the means $\pm S E$ of three independent measurements. The SCNs for a determination were pooled from three animals and assayed in triplicate by EIA. Values are expressed as femtomoles per bilateral SCNs of an animal. $d$, Time course of the effect of continuous dark exposure on NPY-LI in the SCN. Following various durations (2-24 hr) of dark exposure at CT12, NPY-LI levels were measured. Protocol of illumination is illustrated in Figure 1d. Points and bars represent the means \pm SE of three independent measurements. The SCNs for a determination were pooled from three animals and assayed in triplicate by EIA. Values are expressed as femtomoles per bilateral SCNs of an animal.

tent in the SCN (Sodersten et al., 1985; Tominaga et al., 1992) paralleled the manner of AVP release into medium of the cultured SCN (Gillette and Reppert, 1987) or in to the cerebrospinal fluid (Reppert et al., 1987). Therefore, changes in peptide contents by light conditions in the present study might well reflect, in a way, changes in the synthesis and release of peptides.

The first series of experiments demonstrated that VIP-LI in the SCN exhibited a rhythm only in the LD regimen; VIP-LI increased during the dark period and decreased during the light period. A similar daily pattern of VIP-LI was previously re- ported by Morin et al. (1991) using radioimmunoassay and Takahashi et al. (1989) using quantitative immunohistochemistry. We found no significant daily variation of VIP-LI in DD. Since no rhythm in VIP mRNA in the SCN was reported in DD (Takeuchi et al., 1992), it is possible that synthesis and release of VIP are also constant during the day. In the present study, we further examined in detail the effect of illumination for various durations (longest, $36 \mathrm{hr}$ ) on VIP-LI levels. We found that VIP-LI levels in the SCN continued to decrease for more than $12 \mathrm{hr}$ (half a day) during light exposure. VIP-LI reached a 
minimal level after $16 \mathrm{hr}$ and did not change further in the light at least until $36 \mathrm{hr}$. An interpretation from the functional point of view is that VIP follows the duration of illumination up to a certain duration. Saturation at about $16 \mathrm{hr}$ indicates the capacity of VIP to recognize the duration of illumination. Recently, there have been reports that SCN levels of VIP/PHI mRNA were found to be higher at night than in the day in LD (Gozes et al., 1989; Stopa et al., 1989). Enucleation of the eyes elevated VIP/PHI mRNA levels in the SCN (Holtzman et al., 1989). Similar responsiveness to light found for both VIP and VIP mRNA content suggests that VIP content may be regulated by VIP synthesis.

There were diurnal changes in GRP-LI under LD conditions, but no significant changes were observed under DD conditions. In contrast to VIP-LI, GRP-LI steadily increased in the light phase and decreased in the dark phase. A similar type of variations was recently reported in GRP mRNA levels using quantitative in situ hybridization analysis (Albers et al., 1991a). The study of continuous light exposure revealed that GRP could alter its levels for $12 \mathrm{hr}$ (less than a half a day) with increasing exposure time. The capacity of GRP to recognize the duration of photic stimuli (about $12 \mathrm{hr}$ ) seemed to be smaller than that of VIP (about $16 \mathrm{hr}$ ).

During the light phase, VIP-LI and GRP-LI in the SCN showed a progressive decrease and increase, respectively. Monotonic changes in VIP and GRP contents suggested that VIP and GRP transmit visual information on duration of illumination to the pacemakcr. On the other hand, these changes in peptide contents during the light seem to be consistent with tonic electrophysiological responses to light stimuli reported by Groos and Meijer (1985). They demonstrated that light-activated and light-suppressed cells in the $\mathrm{SCN}$ responded to long-duration light stimuli with a sustained elevation or suppression of their mean discharge. It is interesting to note that two different directions of change were found both in electrical and chemical responses to light in the SCN.

The present results suggest the possibility that although VIP and GRP are colocalized in some cells (Okamura et al., 1986), these peptides carry out different modes of action in processing of light information in the SCN. First, their direction of change in response to light is opposite. Second, the time to reach steady level in response to light is shorter with GRP than with VIP. The anatomical features of the two peptides may reflect these differences. It is noted that most rostrally, VIP-LI cells appear to be somewhat more widely distributed within the ventral half of the nucleus while GRP-containing cells are largely confined to the extreme ventral margin of the SCN (Mikkelsen et al., 1991). In addition, VIP-LI boutons are found throughout the SCN, whereas GRP-LI boutons are restricted to ventrolateral parts of the SCN (Van den Pol and Gorcs, 1986). These observations suggest that VIP-LI neurons receive various inputs and project to both subdivisions of the SCN, while GRP-LI neurons receive restricted inputs and project mainly to the ventrolateral SCN. Indeed, from electron microscopic studies, VIP-LI neurons in the SCN receive several kinds of inputs from neurons immunoreactive for SS (Maegawa et al., 1987), 5-HT (Hisano et al., 1988a), and NPY (Hisano et al., 1988b). Thus, it could be speculated that light suppressed VIP-LI levels in the SCN because visual information was integrated on the VIP neurons with several inhibitory signals, such as SS (Koch and Schonbrunn, 1984), NPY (Shibata and Moore, 1988), and 5-HT (Meijer and Groos, 1988). Although no such information is available for GRP, it could be that the reason why GRP-LI in the SCN showed an increase in the light period is because GRP-containing neurons may receive excitatory visual afferents (Nishino and Koizumi, 1977; Shibata et al., 1984; Mason et al., 1987) lacking other inhibitory inputs.

NPY-LI is the only peptide of the three examined here in the ventrolateral SCN that showed a circadian rhythm in DD. However, this rhythm of NPY-LI was drastically modulated by photic stimulation, which is quite different from the cases of AVP and SS rhythms (Sodersten et al., 1985; Shinohara et al., 1991). Under LD conditions, NPY-LI displayed a bimodal rhythm with peaks at $2 \mathrm{hr}$ after light onset (CT2) and at $2 \mathrm{hr}$ after light offset (CT14). Continuous light and continuous dark exposure revealed that both peaks under LD conditions were actually direct consequences of the light-dark and dark-light transitions. Transient increase at CT2 was detected only when dark-light transition occurred at CTO. The peak was found at $2 \mathrm{hr}$ after light onset in continuous light experiment of Figure $4 c$, and it should be of the same nature as the first peak at CT2 under LD conditions. Without dark-light transition at CT0, this first peak was not detected in continuous dark exposure experiment, where CT 2 corresponded to $14 \mathrm{hr}$ after dark onset (Fig. 4d). The second peak in the LD cycle also arises from a direct effect of lightdark transition at CT12 because a significant rise in NPY-LI levels was only seen at transitional period of CT14 in the dark exposure experiment (Fig. $4 d$ ) and no rise was detected at 12 $\mathrm{hr}$ and $16 \mathrm{hr}$ after light on in the light exposure experiment (Fig. $4 c$ ) in which there was no light transition at CT12. Altogether, the two peaks of the NPY-LI rhythm in the SCN under LD cycles ought to mediate information to the pacemaker on the photic transition, either from dark to light or from light to dark.

The endogenous peak found in DD (Fig. $4 a$ ) seems to be caused by a different mechanism from that for the peaks induced by the LD transition, although the second peak in LD and the endogenous peak occurred at a similar time. If a peak was endogenously generated by the pacemaker, the peak would appear every $24 \mathrm{hr}$. However, the endogenous peak was detected neither at $12 \mathrm{hr}$ after light on (CT12) in the light exposure (Fig. 4c) nor at $24 \mathrm{hr}$ after light off (CT12) in the dark exposure (Fig. 4d). Consistent with all these results is the possibility that a transition between light and dark could eliminate the endogenous peak in $24 \mathrm{hr}$ after the transition (Fig. $4 c, d$ ) and that the endogenous peak might appear in the prolonged constant darkness (more than $48 \mathrm{hr}$ ) as shown in Figure $4 a$.

Rhythms in NPY-LI under LD conditions were previously studied using quantitative immunohistochemistry (Calza et al., 1990) and radioimmunoassay (Jhanwar-Uniyal et al., 1991). Although both authors reported a bimodal daily pattern in NPYLI in the SCN, our data agree better in detail with those of Calza and colleagues. In the Jhanwar-Uniyal et al. report, the second peak occurred before the onset of the dark, a result that was not reproduced in the present study.

In the present study, two peptides that are contained in the cell bodies within the ventrolateral SCN, VIP and GRP, did not show endogenous circadian rhythms but showed induced rhythms by environmental lighting cycles. One other member of the peptide family in the ventrolateral SCN, NPY, which is distributed in the axon terminals within this subdivision, displayed an endogenous circadian rhythm, but the daily pattern in the LD cycle was also drastically different. These results, in combination with the results of exogenous injection of peptides in the ventrolateral $\mathrm{SCN}$, lead us to the proposition that peptides 
in the ventrolateral SCN may act on the input side to the pacemaker, or that these peptides might have functional significance in the process of photic entrainment in the SCN.

On the other hand, the dorsomedial SCN neurons contain AVP and SS (Van den Pol and Tsujimoto, 1985). These peptides have two general features different from those of ventrolateral peptides: they show circadian rhythms with peaks during early subjective day (Sodersten et al., 1985; Reppert et al., 1987; Shinohara et al., 1991a; Tominaga et al., 1992), and these rhythms persist in the absence of environmental lighting cues without much change in circadian pattern (Reppert et al., 1987; Shinohara et al., 1991; Tominaga et al., 1992). In contrast to peptides in the ventrolateral SCN, peptides in the dorsomedial SCN could be implicated in outward mediation of the generated rhythms or in internal generation of circadian rhythms.

Subdivisions in the SCN, which have been characterized by the differential arborization of visual afferents and by the segregation of chemically distinct neuronal populations, now may also be distinguished by the behavior of peptides in response to light. The peptide contents in the ventrolateral SCN are mainly regulated by photic stimulation, whereas the dorsomedial peptides are independent of lighting conditions. The present results add additional evidence that the two subdivisions of the SCN (dorsomedial and ventrolateral) are involved in distinct functions of the circadian clock system located in this nucleus.

\section{References}

Albers HE, Ferris CF (1984) Neuropeptide Y: role in light dark cycle entrainment of hamster circadian rhythm. Neurosci Lett 50:163-168.

Albers HE, Minamitani N, Stopa F, Ferris CF (1987) Light selectively alters vasoactive intestinal peptide and peptide histidine isoleucine immunoreactivity within the rat suprachiasmatic nucleus. Brain Res 437:189-192.

Alhers HE, Liou SY, Ferris CF, Stopa FG, 7oeller RT (1991a) Neurochemistry of circadian timing. In: Suprachiasmatic nucleus (Klein DC, Moore RY, Reppert SM, eds), pp 263-288. New York: Oxford UP.

Albers HE, Liou SY, Stopa EG, Zoeller RT (1991b) Interaction of colocalized neuropeptides: functional significance in the circadian timing system. J Neurusci 11:846-851.

Calza L, Giardino L, Zanni M, Velard A, Parchi P, Marrama P (1990) Daily changes of neuropeptide $Y$-like immunoreactivity in the suprachiasmatic nucleus of the rat. Regul Pept 27:127-137.

Gillette MU, Reppert SM (1987) The hypothalamic suprachiasmatic nuclei: circadian patterns of vasopressin secretion and neural activity in vitro. Brain Res Bull 19:135-139.

Gozes I, Shani Y, Liu B, Burbach JPH (1989) Diurnal variation in vasoactive intestinal peptide messenger RNA in the suprachiasmatic nucleus of the rat. Neurosci Res Commun 5:83-86.

Groos GA, Meijer JH (1985) Effect of illumination on suprachiasmatic nucleus electrical discharge. Ann NY Acad Sci 453:134-146.

Hisano S, Chikamori-Aoyama M, Katoh S, Maegawa M, Daikoku S (1988a) Immunohistochemical evidence of serotonergic regulation of vasoactive intestinal polypeptide (VIP) in the rat suprachiasmatic nucleus. Histochemistry 86:573-578.

Hisano S, Chikamori-Aoyama M, Katoh S, Kagotani Y, Daikoku S, Chihara K, Takahashi Y (1988b) Suprachiasmatic nucleus neurons immunoreactive for vasoactive intestinal peptide have synaptic contacts with axons immunoreactive for neuropeptide $Y$ : an immunoelectron microscopic study in the rat. Neurosci Lett 88:145-150.

Holtzman RL, Malach R, Gozes I (1989) Disruption of the optic pathway during development affects vasoactive intestinal peptide mRNA expression. New Biol 1:215-221.

Jhanwar-Uniyal M, Beck B, Buret C, Leibowitz SF (1991) Diurnal rhythm of neuropeptide $Y$-like immunoreactivity in the suprachiasmatic, arcuate and paraventricular nuclei and other hypothalamic sites. Brain Res 536:331-334.

Koch BD, Schonbrunn A (1984) The somatostatin receptor is directly coupled to adenyl cyclase in $\mathrm{GH}_{4} \mathrm{C}_{1}$ pituitary cell membranes. Endocrinology 114:1784-1790.
Maegawa M, Hisano S, Tsuruo Y, Katoh S, Nakanishi J, ChikamoriAoyama M, Daikoku S (1987) Differential immunolabeling for electron microscopy of diverse peptidergic neurons. J Histochem Cytochem 35:251-255.

Mason R, Harrington ME, Rusak B (1987) Electrophysiological responses of hamster suprachiasmatic neurones to neuropeptide $Y$ in the hypothalamic slice preparation. Neurosci Lett 80:173-179.

Meijer JH, Groos GA (1988) Responsiveness of suprachiasmatic nucleus and ventral geniculate neurons to serotonin and imipramine: a micro-iontophoretic study in normal and imipramine-treated rats. Brain Res Bull 20:89-96.

Mikkelsen JD, Larsen PJ, O'Hare MMT, Wiegand SJ (1991) Gastrin releasing peptide in the rat suprachiasmatic nucleus: an immunohistochemical, chromatographic and radioimmunological study. Neuroscience 40:55-66.

Moore RY, Card JP (1985) Visual pathways and the entrainment of circadian rhythms. Ann NY Acad Sci 453:123-133.

Morin A, Denoroy L, Jouvet M (1991) Daily variations in concentration of vasoactive intestinal polypeptide immunoreactivity in discrete brain areas of the rat. Brain Res 538:136-140.

Nishino H, Koizumi K (1977) Response of neurons in the suprachiasmatic nuclei of the hypothalamus to putative transmitters. Brain Res 120:167-172.

Okamura H, Murakami S, Uda K, Sugano T, Takahashi Y, Yanaihara C, Yanaihara N, Ibata $Y$ (1986) Coexistence of vasoactive intestinal peptide (VIP)-, peptide histidine isoleucine amide (PHI)-, and gastrin releasing peptide (GRP)-like immunoreactivity in neurons of the rat suprachiasmatic nucleus. Biomed Res 7:295-299.

Okamura H, Takahashi Y, Terubayashi H, Hamada S, Yanaihara N, Ibata Y (1987) VIP-like immunoreactive neurons and retinal projections in the rat suprachiasmatic nucleus. Biomed Res 8:253-262.

Palkovits M, Brownstein MJ (1985) Distribution of neuropeptides in the central nervous system using biochemical micromethod. In: Handbook of chemical neuroanatomy, Vol 4 (Bjorklund A, Hokfelt T, eds), pp 1-71. Amsterdam: Elsevier.

Reppert SM, Schwartz WJ, Uhl GK (1987) Arginine-vasopressin: a novel peptide rhythm in cerebrospinal fluid. Trends Neurosci 10:7680.

Shibata S, Moore RY (1988) Neuropeptide Y and vasopressin effects on rat suprachiasmatic nucleus neurons in vitro. J Biol Rhythms 3:265276.

Shibata S, Liou SY, Ueki S, Oomura Y (1984) Influence of environmental light-dark cycle and enucleation on activity of suprachiasmatic neurons in slice preparations. Brain Res 302:75-81.

Shinohara K, Isobe Y, Takeuchi J, Inouye SIT (1991a) Circadian rhythms of somatostatin-immunoreactivity in the suprachiasmatic nucleus of the rat. Neurosci Letl 129:59-62.

Shinohara K, Tominaga K, Isobe Y, Inouye SIT (1991b) Photic regulation of peptides located in the ventrolateral SCN of the rats. Soc Neurosci Abstr 17:669.

Sodersten P, De Vries GJ, Buijs RM, Melin P (1985) A daily rhythm in behavioral vasopressin sensitivity and brain vasopressin concentration. Neurosci Lett 58:37-41.

Stopa EG, Minamitani N, Jonassen JA, King JC, Wolfe H, Mobtaker $\mathrm{H}$, Albers HE (1989) Localization of vasoactive intestinal peptide and peptide histidine isoleucine immunoreactivity and mRNA within the rat suprachiasmatic nucleus. Mol Brain Res 4:319-325.

Takahashi Y, Okamura H, Yanaihara N, Hamada S, Fujita S, Ibata Y (1989) Vasoactive intestinal peptide immunoreactive neurons in the rat suprachiasmatic nucleus demonstrate diurnal variation. Brain Res 497:374-377.

Takeuchi J, Nagasaki H, Shinohara K, Inouye SIT (1992) A circadian rhythm of somatostatin messenger RNA levels, but not of vasoactive intestinal polypeptide/peptide histidine isoleucine messenger RNA levels in rat suprachiasmatic nucleus. Mol Cell Neurosci 3:29-35.

Tominaga K, Shinohara K, Otori Y, Fukuhara C, Inouye SIT (1992) Circadian rhythms in vasopressin content in the suprachiasmatic nucleus of the rat. Neuro Report 3:809-812.

Van den Pol AN (1980) The hypothalamic suprachiasmatic nucleus of rat: intrinsic anatomy. J Comp Neurol 191:661-702.

Van den Pol AN, Gorcs T (1986) Synaptic relationships between neurons containing vasopressin, gastrin-releasing peptide, vasoactive intestinal polypeptide, and glutamate hydroxylase immunoreactivity in the suprachiasmatic nucleus: dual ultrastructural immunocyto- 
chemistry with gold-substituted silver peroxidase. J Comp Neurol 252:507-521.

Van den Pol AN, Powley T (1979) A fine-grained anatomical analysis of the role of the rat suprachiasmatic nucleus in circadian rhythms of feeding and drinking. Brain Res 160:307-326.

Van den Pol AN, Tsujimoto KL (1985) Neurotransmitters of the hypothalamic suprachiasmatic nucleus: immunohistochemical analysis of 25 neuronal antigens. Neuroscience 15:1049-1086. 